\title{
METHOD OF CONVERSION OF HIGH- AND MIDDLE-SPEED DIESEL ENGINES INTO GAS DIESEL ENGINES
}

\author{
UDC 629.1
}

\author{
Mikhail G. Shatrov, Vladimir V. Sinyavski, Andrey Yu. Dunin, \\ Ivan G. Shishlov, Andrey V. Vakulenko \\ Energo-Ecological Faculty, \\ Moscow Automobile and Road Construction State Technical University (MADI), \\ Moscow, Russia
}

\begin{abstract}
The paper aims at the development of fuel supply and electronic control systems for boosted high- and middle-speed transport engines. A detailed analysis of different ways of converting diesel engine to operate on natural gas was carried out. The gas diesel process with minimized ignition portion of diesel fuel injected by the Common Rail (CR) system was selected. Electronic engine control and modular gas feed systems which can be used both on high-and middle-speed gas diesel engines were developed. Also diesel CR fuel supply systems were developed in cooperation with the industrial partner, namely, those that can be mounted on middle-speed diesel and gas diesel engines. Electronic control and gas feed systems were perfected using modeling and engine tests. The high-speed diesel engine was converted into a gas diesel one. After perfection of the gas feed and electronic control systems, bench tests of the high-speed gas diesel engine were carried out showing a high share of diesel fuel substitution with gas, high fuel efficiency and significant decrease of $\mathrm{NO}_{x}$ and $\mathrm{CO}_{2}$ emissions.
\end{abstract}

Key Words: Gas Diesel Engine, Engine Control System, Gas Feed System, Diesel Fuel Supply System, High-speed Engine, Middle-speed Engine

\section{INTRODUCTION}

At present, natural gas is considered to be one of the most promising types of alternative fuels. The proven resources of gas on the Earth are much higher than those of oil. Natural gas is cheaper than oil and the engines fueled by it have significantly cleaner exhaust emissions compared with diesel, especially particles. In 2010, the share of natural

Received: October 04, 2017 / Accepted November 16, 2017

Corresponding author: Vladimir Sinyavski

Moscow Automobile and Road Construction State Technical University (MADI), Energo-Ecological Faculty, Russia 125319 Moscow, Leningradski pr., 64

E-mail: sinvlad@mail.ru 
gas in the world balance of gaseous alternative fuels exceeded 50\%. It is forecasted that the share of natural gas will increase to 5.1 billion tons by 2035 and its share in the fuel balance of our planet will increase up to $25 \%$ [1,2].

Diesel engine may be converted into spark ignition gas engine operating on a stoichiometric gas-air mixture. The advantages are stable gas combustion and the possibility of using a three-way catalyst similar to that mounted on petrol engines. The location and geometry of the gas supply valves in the intake manifold significantly influence engine operation parameters [3]. Using a stoichiometric gas-air mixture does not improve fuel economy compared with diesel engine, but taking into account the fact that natural gas is almost twice cheaper in Russia than diesel fuel, expenses for fuel are much lower. The research of fuel consumption by buses having different powertrains running along three different routes show that the buses having the gas engines with stoichiometric gas-air mixture consumed by $10-25 \%$ more fuel than those with diesel engine. As natural gas is by $52 \%$ cheaper than diesel fuel in Serbia, expenses for gas fuel are considerably lower [4]. Stoichiometric gas engines have a high temperature of exhaust gases that is dangerous for turbocharger and impedes high boosting.

In lean mixture gas engines, the exhaust gases temperature is low and this enables them to have high boosting, high fuel efficiency and low $\mathrm{NO}_{\mathrm{x}}$ emissions which makes it possible to avoid the use of a reduction catalyzer. For middle-speed gas engines operating on a lean gas-air mixture, the prechamber with enriched mixture is used to inflame and control the lean mixture combustion in the main combustion chamber. The FEV company developed a prechamber system for gas engine operating on a lean gas-air mixture. To attain the most efficient combustion without knock and low emissions of NOx, the number and size of the prechamber holes, their orientation and prechamber size were investigated. A moderate Miller cycle was used. Calculations were fulfilled using the Charge Motion Design (CMD) package which made it possible to investigate the influence of turbulence on the combustion process. Experiments were carried out on a one-cylinder 161 diesel engine modified for operation on natural gas. After simulation and experimental perfection, the indicated mean effective pressure reached 32 bars, the engine operated without knock and the $\mathrm{NO}_{\mathrm{x}}$ emissions were within the limits of the TA-Luft standard [5].

Jenbacher J624 (type 6) gas engines having D/S=190/210 mm used for electric power generation operating at $1500 \mathrm{rpm}$ on a lean gas-air mixture having a gas enriched prechamber attain a high brake mean effective pressure of $2.4 \mathrm{MPa}$. Here, the advanced Miller cycle is implemented to avoid knock which also ensures high thermal efficiency up to $48.7 \%$ and reduces $\mathrm{NO}_{\mathrm{x}}$ emissions. A two-stage turbocharging system is used to compensate for filling efficiency drop caused by the Miller cycle and it also increases the engine effective efficiency by few percent compared with one-stage turbocharging [6,7]. This is a very good solution for power generation because the engine operates all the time at a high constant speed which enables it to avoid knock. Less fuel efficiency compared with gas diesel engines is compensated by a $\mathrm{NO}_{\mathrm{x}}$ much lower price of gas when stationary engines are connected directly to gas pipelines. In Russia, gas from the pipeline may be up to 4 times cheaper than that at the gas filling station [3]. The use of this working process on average-speed high boosted transport engines is impeded by knock which originates at low speeds and transfer modes especially for engines having a large cylinder bore. 
Gas diesel (or dual-fuel) engines do not have problems of knock. They may have a large size and high boosting. In gas diesel engines using a traditional (mechanical) gas fuel feed system, substitution of diesel fuel by gas is comparatively low because the share of diesel fuel is $20-30 \%$ at full loads, it grows with decrease of load and becomes $100 \%$ at idle speed [8]. The share of diesel fuel can be lowered if a special HP fuel pump for injecting small portions of diesel fuel is used [9]. Substitution of diesel fuel by gas can be increased and most of the engine parameters can be significantly improved in "New Generation" gas diesel engines using a minimized portion of diesel fuel injected by the Common Rail (CR) system for ignition of the gas-air mixture.

The analyses conducted in the Moscow State Technical University named after N.Bauman [10] showed that the larger fuel sprays are, the higher is ignition stability of the gas and the lower may be the ignition portion of diesel fuel. If the injector nozzle holes are unchanged, the size of the fuel sprays is determined mainly by the diesel fuel injection pressure (if the pressure increases, the fuel drops are smaller and the fuel spray surface is larger), the speed and direction of gas movement during the compression stroke (if the speed increases, the mixture formation and combustion of the gas-air mixture improve), and the backpressure in the cylinder (if the backpressure increases, the diesel fuel atomization is more efficient). When the engine speed and load decrease, the pressure and speed of the working medium in the cylinder are lower, also the backpressure drops due to lower boost pressure provided by the turbocharger. Therefore, a small portion of ignition diesel fuel which can be less than 5\% at high load has to be increased at low loads. It is possible to increase the size of the fuel sprays by raising the injection pressure and using a special baffled piston to increase the tangential speed of the gases. In the same paper, a special design of the traditional type fuel system injector is offered which ensures stable injection of small ignition portions of diesel fuel. The injector has a deformable rest. At low injection pressures corresponding to low engine loads, the injector needle valve bumps against a deformable rest and its small lift is stable from cycle to cycle. At higher injection pressures, the rest is deformed and the needle valve lifts to its full height.

The combustion process of a gas diesel engine with direct injection of gas into the cylinder (GI engine) was investigated at the Kyushu University using a Rapid CompressionExpansion Machine (RCEM) [11]. The propagation of flame bodies of diesel and gas fuel during the combustion process was fixed using high-speed cameras via windows in the cylinder head. The intake air turbulence was changed by variation of the location of the intake valve. The EGR was imitated by decreasing the content of oxygen in the intake air from $21 \%$ to $17.5 \%$. Increasing the turbulence by the intake air resulted in the growth of the rate of heat release and a considerable decrease of unburned gas. Emissions of $\mathrm{NO}_{\mathrm{x}}$ in the GI engine were by $25 \%$ lower than in the diesel engine without EGR. The EGR enabled to decrease emissions of $\mathrm{NO}_{\mathrm{x}}$ additionally by $75 \%$ which was visually confirmed by less brightness of the flame body corresponding to lower combustion temperature.

In [12], the problems of combustion in gas diesel engines are addressed: high unburned $\mathrm{HC}$ and $\mathrm{CO}$ emissions due to incomplete combustion in some zones especially at low load operation, cycle to cycle instability at high loads. To cope with this, a number of parameters should be thoroughly controlled: pilot dose of diesel fuel and its phasing, diesel fuel injection timing, quantity of gas, quantity and temperature of air entering the cylinder taking into account engine speed and load. The best way is to use a fast and efficient control algorithm. A 
simple 0-dimensional model for simulation of combustion in gas diesel engine was developed to be used for engine control. It is based on Vibe formula for diesel fuel combustion; it takes into account heat exchange with the walls and variation of thermodynamic parameters of the working medium. Combustion of the natural gas is based on one-step macro reactions of the main components of the mixture. After validation of the model using the results of testing at four-cylinder 2.6361 gas diesel engine, it provides a pretty high agreement of calculated and experimental results.

The problem of the gas diesel engines with minimized portion of ignition diesel fuel is probable overheating of the nozzles of standard CR injectors because of their poor cooling by fuel when only $3-5 \%$ of diesel fuel is injected. The solution may be to mount the CR fuel system of a smaller engine for which a 3-5\% percent ignition portion of diesel fuel amounts almost to full-load fuel supply. In this case, the engine will not be able to operate on diesel fuel only though a reliable gas supply can be ensured for many applications, for example for locomotives and dump trucks that move along fixed routes.

On the basis of the analysis carried out, the gas diesel engine using a minimized portion of diesel fuel supplied by the CR system that injects fuel at high pressure at any operation mode was chosen for high- and middle-speed engines because it enables high boosting, engine efficiency, ecological parameters; also, it avoids knock.

\section{METHOd of DEVELOPMENT OF FuEl FEed AND ELECTRONIC CONTROL SySTEMS FOR HIGH- AND MIDDLE-SPEED GAS DIESEL ENGINES}

MADI participated in the state programs of development of gas feed and electronic engine control systems for high and middle-speed engines fueled by natural gas and of development of CR diesel fuel supply systems for diesel and gas diesel engines. A highspeed diesel engine was available in MADI and a middle-speed engine - not available because its mass production has not yet started. Therefore, a method for development of fuel feed and engine control systems for a middle-speed gas diesel engine using a highspeed gas diesel engine as a mockup was proposed which included the following steps:

- Development of electronic engine control system and modular gas feed system suitable for both the high- and middle-speed gas engines;

- Perfection of both the systems during engine tests on a high-speed gas diesel engine using the diesel fuel supply system of the base diesel engine;

- Development of fuel supply system for the middle-speed gas diesel engine jointly with the industrial partner.

\section{RESEARCH OBJECTS}

The research was carried out for two in-line 6-cylinder gas diesel engines: high-speed automobile Cummins KAMA engine that was used for experimental perfection of modular gas supply and electronic engine control systems and middle-speed locomotive D200 engine whose mass production has not yet started. The operation parameters of the D200 gas diesel engine were calculated. CR diesel fuel supply system and turbocharging system with the bypass valve at the turbine inlet of the base Cummins KAMA diesel 
engine were used for the gas diesel version. The main parameters of the two base diesel engines are presented in Table 1.

Table 1 Main parameters of two engines investigated

\begin{tabular}{lccccc}
\hline Base diesel engine & $\begin{array}{c}\text { Cylinder } \\
\text { diameter } \\
(\mathrm{mm})\end{array}$ & $\begin{array}{c}\text { Cylinder } \\
\text { stroke }(\mathrm{mm})\end{array}$ & $\begin{array}{c}\text { Rated } \\
\text { speed } \\
(\mathrm{rpm})\end{array}$ & $\begin{array}{c}\text { Rated break mean } \\
\text { effective pressure } \\
(\mathrm{MPa})\end{array}$ & $\begin{array}{c}\text { Compression } \\
\text { ratio }\end{array}$ \\
\hline $\begin{array}{l}\text { Locomotive D200 } \\
\text { Automobile }\end{array}$ & 200 & 280 & 1000 & 2.0 & $14.0: 1$ \\
Cummins KAMA & 107 & 124 & 2300 & 1.73 & $17.3: 1$ \\
\hline
\end{tabular}

\section{ENGINE SYSTEMS DEVELOPED}

For conversion of high- and middle speed diesel engines into gas diesel ones, electronic engine control, modular gas feed and CR fuel supply systems were developed.

\subsection{Electronic engine control system}

A completely new electronic engine control system for 6-cylinder gas diesel engines was developed which controls supply of gaseous and diesel fuel (Fig. 1). The system generates electric control impulses to control actuators; it carries out synchronization and distribution of impulses by the cylinders depending on the engine operation mode on the basis of information received from many sensors.

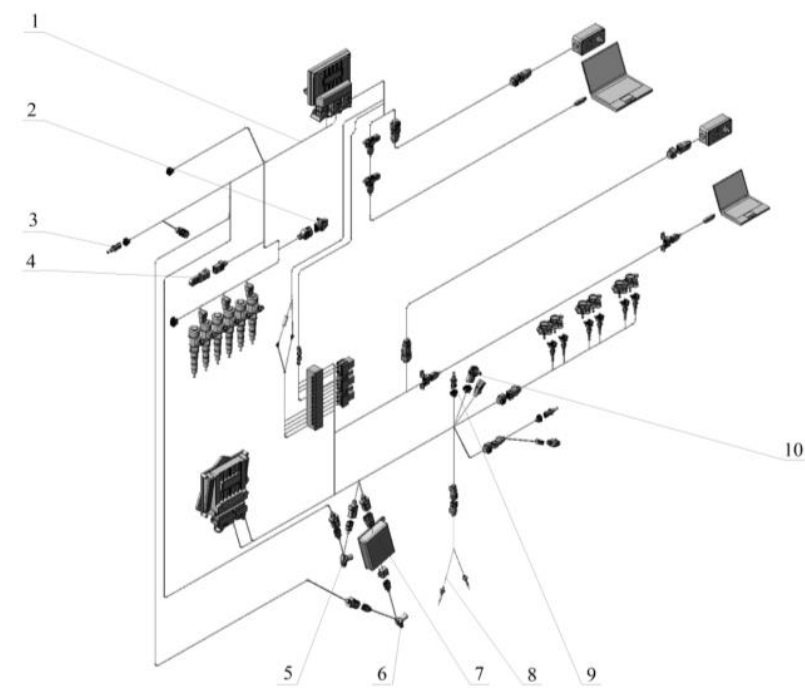

Fig. 1 Components of the electronic engine control system for gas diesel engines: 1 - information-calculation block; 2, 10 - intake manifold temperature and pressure sensors; 3, 9 - cooling agent temperature sensors; 4 - barometric correction sensor; 5 - crankshaft position sensor; 6 - camshaft position sensor; 7 - crankshaft and camshaft position sensors adapter; 8 - block of thermocouples 


\subsection{Modular gas feed system}

The gas feed system has a modular architecture. Each module (Fig. 2) ensures pressure reduction as well as a supply of natural gas. This enables us to use a different number of modules depending on the engine size. One module is used on the high-speed Cummins KAMA gas diesel engine and three modules - on the middle-speed D200 gas diesel engine. The gas feed system ensures a supply of natural gas under working pressure of $1 \mathrm{MPa}$ for the gas diesel engine with external mixture formation. It has metering valves with electronic control. When three modules are mounted on the D200 engine, three gas supply valves for each cylinder are used: two small valves of the Cummins KAMA engine for injection of small portions of gas at idle and one large valve - at high loads.

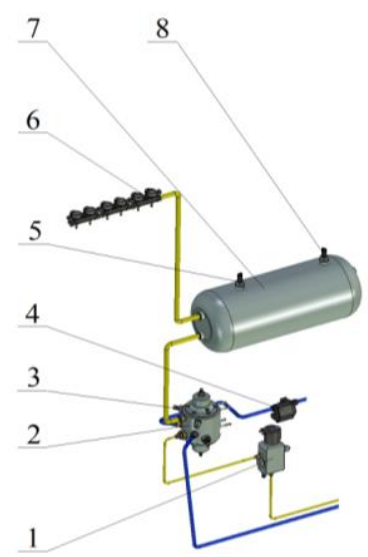

Fig. 2 One module of gas supply system for the gas diesel engine:

1 - main high pressure solenoid valve; 2 - two-stage gas pressure reducer;

3 - pressure and temperature sensors in the reducer; 4 - cooling agent controller;

5 - gas pressure sensor; 6 - gas supply valves; 7 - gas receiver; 8 - gas

temperature sensor

\subsection{CR fuel supply system for the middle-speed gas diesel engine}

In partnership with the industrial partner - Noginsk Factory of Fuel Systems OJSC, two CR fuel systems were developed which may be used for both middle-speed diesel and gas diesel engines complying with the ecological standards Stage IIIB:

- D200 (6-cylinder, D/S=200/280 mm) manufactured by Penzadieselmash OJSC,

- M150M (12-cylinder, D/S=150/175 mm) manufactured by Zvezda OJSC,

- DM185T (6-cylinder, D/S=185/215 mm, 12-cylinder $\mathrm{D} / \mathrm{S}=185 / 215 \mathrm{~mm}, 16$ cylinder $\mathrm{D} / \mathrm{S}=185 / 215 \mathrm{~mm}, 20$-cylinder $\mathrm{D} / \mathrm{S}=185 / 215 \mathrm{~mm}$ ) manufactured by Ural Diesel Engine Factory OJSC.

To get the highest possible commonality of the model line, the CR fuel systems of the aforementioned engines consist of the maximal possible number of identical components. The layout of the CR fuel system mounted on the 6-cylinder engine with $D / S=200 / 280 \mathrm{~mm}$ is shown as an example (Fig. 3). The high pressure (HP) fuel pump includes six plunger sections located in radial direction by pairs along the circle over $120^{\circ}$ (Fig. 4). 


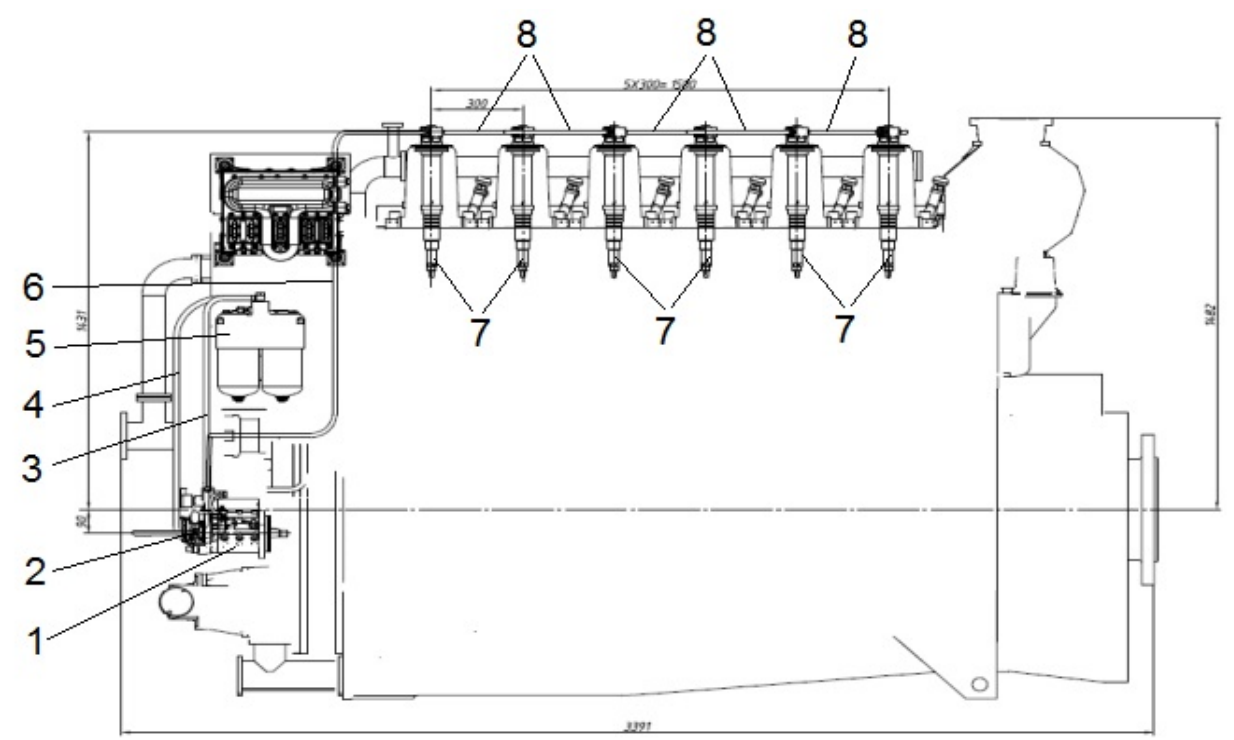

Fig. 3 Layout of the CR fuel system on the 6-cylinder diesel engine D/S=200/280 mm: 1 - HP fuel pump; 2 - fuel feed pump; 3 - low pressure fuel line from the fine fuel filter to the HP fuel pump; 4 - low pressure fuel line from the pump 2 to the fine fuel filter; 5 - fine fuel filter; 6 - fuel line from the fuel pump to the first cylinder injector; 7 - CR injector (CRI); 8 - fuel lines between the injectors

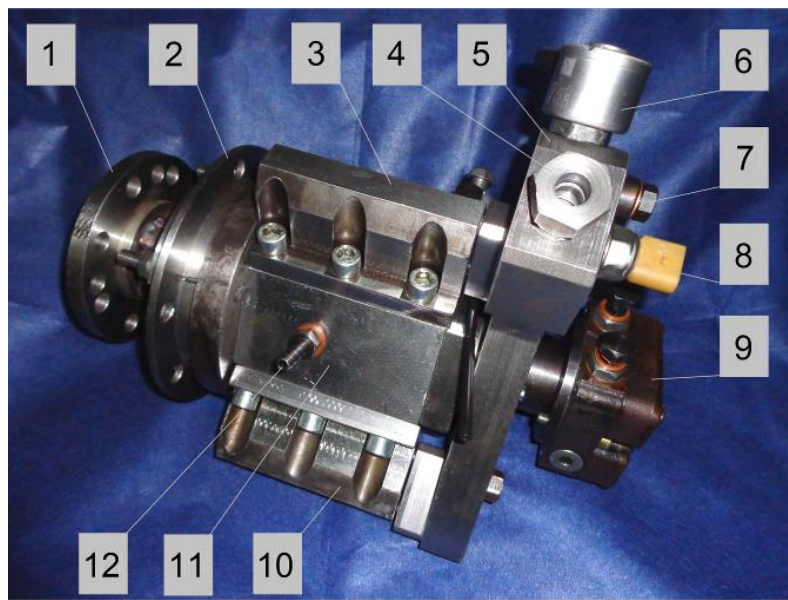

Fig. 4 Test model of the HP fuel pump:

1,2 - flanges of the shaft drive and fastening to the cylinder block correspondingly; 3 - head of delivery sections; 4 - nut of high pressure fuel line; 5 - common rail; 6 - solenoid valve; 7,12 - fittings of the low pressure fuel line and lubricating system correspondingly; 8 - pressure sensor; 9 - fuel feed pump; 10 - bolts fastening fuel pump heads; 11 - fuel pump body 
The plungers located in one row operate in the reversed phase - the delivery cycles take place at every $180^{\circ}$ of the crankshaft rotation. In this case, the HP fuel pump cycles of fuel delivery into the high pressure line occur at every $60^{\circ}$. Such a sequence of working strokes of the plungers assures the lower (compared with the in-line arrangement of the HP fuel pump) and uniform load on a drive shaft with eccentric cam (compared with direct action fuel systems). Power consumption of the HP fuel pump drive decreases.

The CR injector (CRI) developed is presented in Fig. 5.

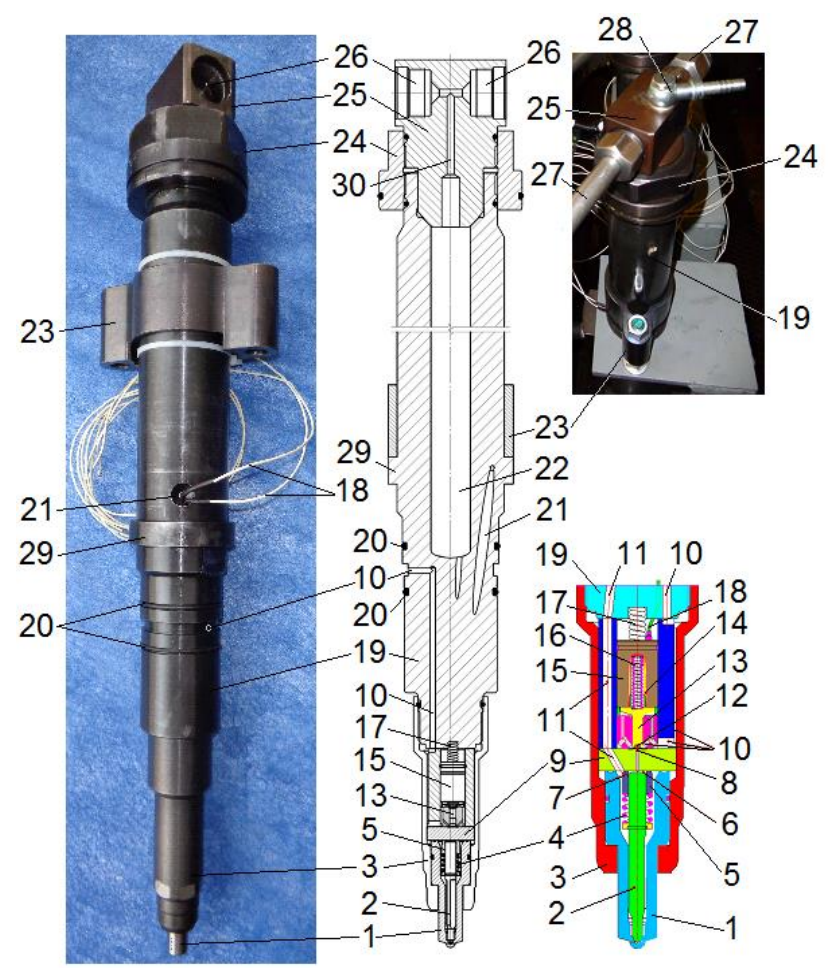

Fig. 5 Test model of the CRI:

1 - nozzle body; 2 - injector nozzle valve; 3 - nozzle nut; 4 - nozzle spring;

5 - floating nozzle bush; 6 - control chamber; 7 - input jet; 8 - output jet;

9 - control valve seat; 10 - control fuel return channels; 11 - channel for fuel input from the common rail of the CRI; 12 - control valve; 13 - armature;

14 - electromagnet core; 15 - electromagnet body; 16 - core spring; 17 - magnet spring; 18 - electromagnet power supply wires; 19 - injector body; 20 - sealing rings; 21 - channel for electromagnet power supply wires; 22 - integrated common rail; 23 - clamping element; 24 - feeder nut; 25 - feeder; 26 - holes for mounting fuel tubes; 27 - high pressure fuel lines; 28 - fitting for return of fuel leaks from the feeder; 29 - thrust collar; 30 - channel for fuel supply to the common rail 
The high pressure common rail 22 is integrated into the injector body 19 in order to smooth the pressure oscillations which originate due to a fluctuating fuel supply from the HP pump and to injectors' operation during the injection process.

The fuel rails of the CRIs are connected to each other by high pressure fuel lines 8 (Fig. 3) via feeders 25 (Fig. 5).

For gas diesel versions of diesel engines D200, M150M and DM185T, a smaller size CR system for supply of the minimized ignition portion of diesel fuel was developed. When developing this experimental CR system, the solutions of design and arrangement of the standard CR systems series on the basis of analysis of the experience of the fuel equipment development for diesel engines was used. The fuel system developed is maximally unified with the CR system of potential consumers of the Industrial partner Noginsk Factory of Fuel Systems CJSC.

The HP pump, fuel lines and CRIs inject fuel under pressure of up to $200 \mathrm{MPa}$ which enables us to obtain high parameters of the combustion process [13]. The fuel used for the CRIs control is drained from every CRI to the low pressure line. The fuel pump has a traditional in-line design, location of plungers in a closed block and inserted fuel supply sections. The cams of the camshaft have an eccentric shape. The delivery valve has a traditional design with discharge collar. The plungers have no grooves: the fuel supply is varied by fuel pressure control in the chamber above the plunger.

With the aim of unification with the base CR system (Fig. 3), dimensions of electrohydraulic valve were preserved and the same floating nozzle bush is used to increase the life time of the CRI.

\section{COMPUTER MODELING}

The parameters of gas diesel engines were calculated by 0 -dimensional model according to the method described in [14] using the Vibe formula for heat release and the Woschni formula for heat losses calculation, empirical formulas for cylinder walls temperature calculation and taking into account composition of the working medium at any instant of the engine cycle. Gas exchange was calculated based on the quasistationary approach while the turbocharger maps were used for calculating parameters at the cylinder inlet and outlet. The model was used for the following aims:

- Calculation of parameters of the high- and middle-speed gas diesel engines required for development and adjustment of the gas feed and electronic engine control systems, and,

- Analysis of experimental parameters obtained during the engine tests of the highspeed gas diesel engine.

\section{RESULTS AND DISCUSSIONS}

The results of the high-speed gas diesel engine tests by the load and external speed characteristics are shown in Figs. 6 and 7.

To check the accuracy of the computer model and analyze the experimental results, the calculations of the engine parameters at all operation modes were carried out and 
compared with the experimental data. The calculations were conducted with the values of gas consumption $G_{g}$ and diesel fuel consumption $G_{d}$ that were used in the experiments with an optimal ignition advance angle for every operation mode.

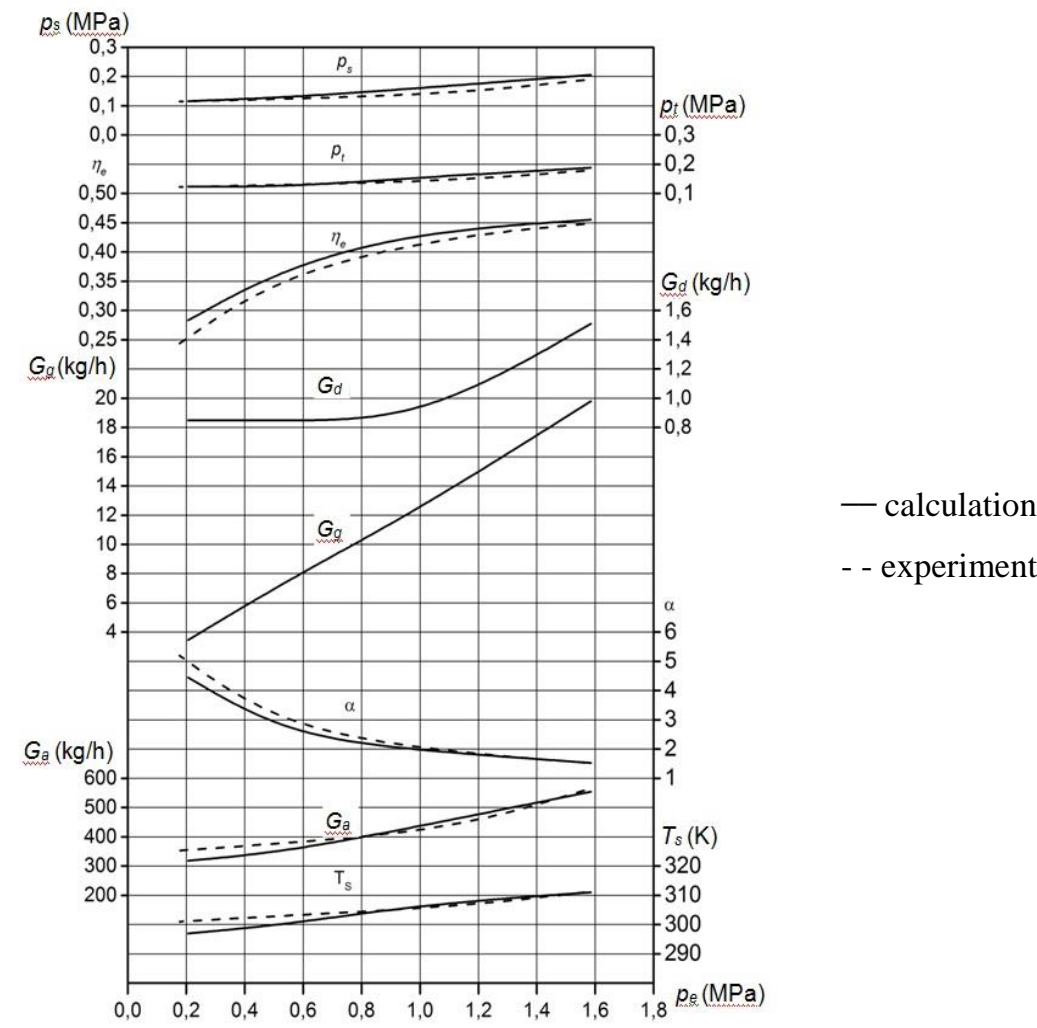

Fig. 6 Load characteristic of the high-speed gas diesel engine Cummins Kama at $n=1420 \mathrm{rpm}$

Figs. 6 and 7 demonstrate a high effective efficiency $\eta_{e}=0.43-45$ at full engine speed and load. There is also a good agreement of calculated and experimental values of boost pressure $p_{s}$, gas pressure before turbine $p_{t}$, air access coefficient $\alpha$, air consumption $G_{a}$, boost air temperature $T_{s}$ and effective efficiency $\eta_{\mathrm{e}}$ at high load and high engine speed. The difference between parameters $G_{a}, \alpha$ and $\eta_{\mathrm{e}}$ increases at low loads (Fig. 6) which may be explained by a not very accurate description of experimental compressor and turbine maps by polynomials at low engine loads.

As seen from Fig. 7, the values of mean effective pressure $p_{e}$ of gas diesel engine are pretty low at low engine speeds. This may be explained by the decrease of the air quantity in the cylinder and hence - air access coefficient $\alpha$ due to a partial substitution of air with gas fuel compared with the base diesel engine. The measured airflow of the gas diesel engine was approximately by $8 \%$ lower than that of the base diesel engine.

Other reasons may be those described in [10]. While in the diesel engine, all the fuel is located in the combustion chamber while in the gas diesel engine, a part of gas 
penetrates into the gaps between the piston/cylinder head and the piston/liner where it burns incompletely. This effect is especially strong at low engine speed when the air turbulence in the combustion chamber is low. This phenomenon is indirectly confirmed by higher calculated effective efficiency $\eta_{e}$ compared with its experimental value at low engine speed (Fig. 7) because poor combustion of fuel in the gaps is not taken into account in the computer model used.

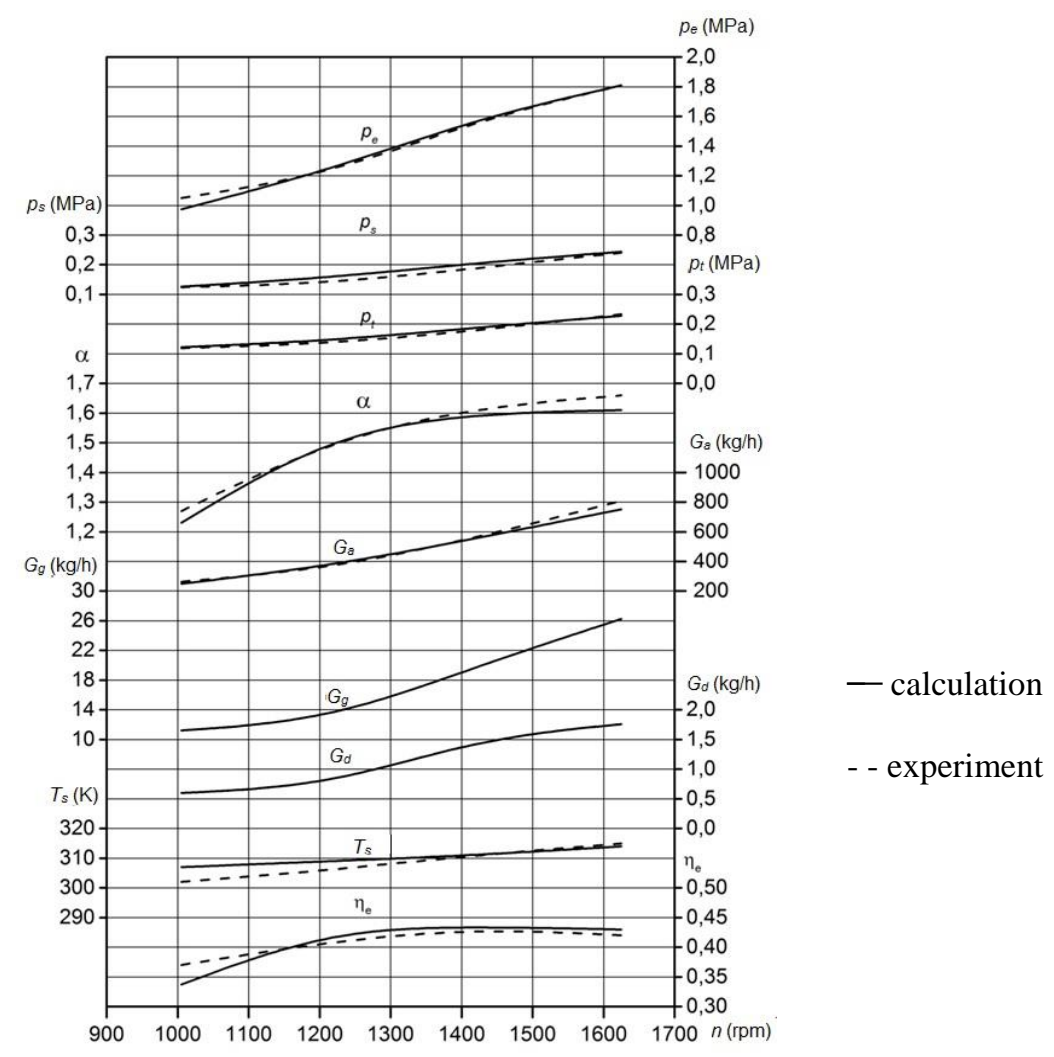

Fig. 7 External speed characteristic of the high-speed gas diesel engine Cummins Kama

Some increase of the mean effective pressure at low engine speeds may be achieved by tuning the turbocharger. But to get as high values of $p_{e}$ as in the base diesel engine, the combustion chamber should be redesigned which requires further in-depth investigations.

Fig. 8 shows the comparison of parameters of the base Cummins KAMA diesel engine and its gas diesel version at three engine speeds and two loads: maximal and partial $(30-40 \%)$. Here the percentage of the ignition portion of diesel fuel to the total amount of fuel is indicated. At full loads, the percentage of diesel fuel is $4.5-6.2 \%$, at low loads $-8.7-8.9 \%$. The percentage of diesel fuel at idle is $33 \%$. On the average, the effective efficiency of the gas diesel engine is by $2 \%$ higher than that of the base diesel engine. $\mathrm{CO}_{2}$ emissions decreased for 1.47 and 1.15 times and of $\mathrm{NO}_{\mathrm{x}}-7.4$ and 1.52 times at full and partial loads, respectively. 


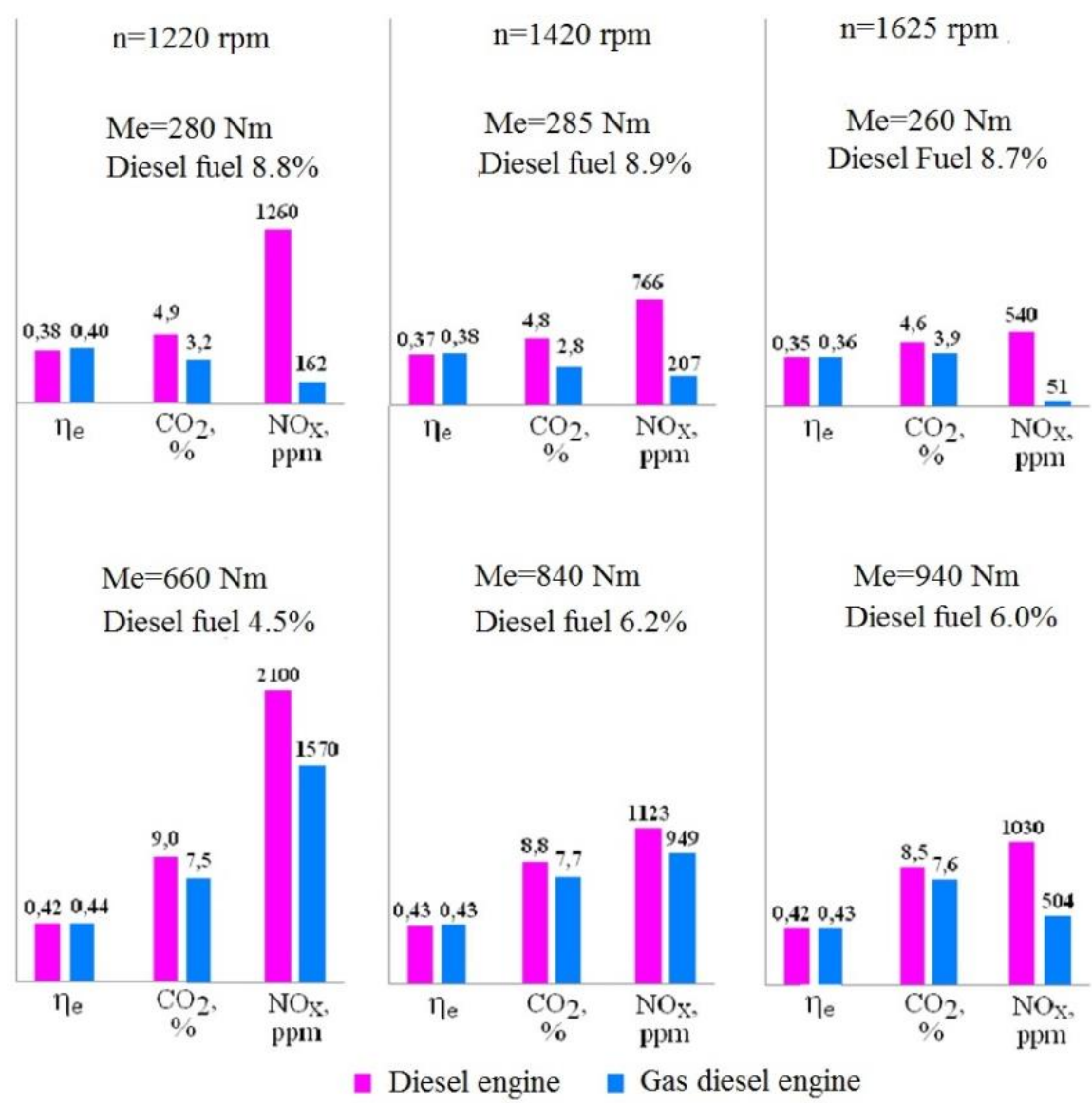

Fig. 8 Comparison of parameters of the high-speed Cummins KAMA base diesel engine with its gas diesel version

\section{CONCLUSION}

1. The analysis conducted demonstrated that the gas diesel process using a minimized igniting portion of diesel fuel supplied by the CR system is the most reasonable way of converting high boosted high- and middle-speed transport diesel engines to operation on natural gas.

2. The modular gas feed system and that of the engine electronic control were developed to be used both on high- and middle-speed gas diesel engines. The base high-speed diesel engine was converted into gas diesel one and used for experimental perfection of these systems.

3. Diesel fuel supply systems were developed for middle-speed engines: they are large in size for injecting full portion of diesel fuel for diesel engine or small in size - for injection of ignition portion of diesel fuel for gas diesel engines. 
4. The gas feed and electronic engine control systems were experimentally perfected and engine characteristics were obtained which demonstrated a high degree of diesel fuel substitution by gas: the average diesel fuel portion amounted to $5.6 \%, 8.8$ and $33 \%$, correspondingly, at full load, approximately $35 \%$ load and idle. $\mathrm{CO}_{2}$ emissions decreased for 1.47 and 1.15 times, of $\mathrm{NO}_{\mathrm{x}}-7.4$ and 1.52 times, respectively, at full and partial loads. Effective efficiency of the gas diesel was on the average by 2 percent higher than that of the base diesel engine.

Acknowledgements: Applied research and experimental developments of fuel feed systems are carried out with financial support of the state represented by the Ministry of Education and Science of the Russian Federation under the Agreement No 14.580.21.0002 of 27.07.2015, the Unique Identifier PNIER: RFMEFI58015X0002.

\section{REFERENCES}

1. Markov, V.A., Gaivoronski, A.I., Grehov, L.V., Ivaschenko, N.A., 2008, Operation of Diesel Engine on NonTraditional Fuels, Legion-Avtodata, Moscow, 464 p.

2. Shatrov, M.G., Khatchijan, A.S., Shishlov, I.G., Vakulenko, A.V., 2008, Analysis of Conversion Methods of Automotive Diesel Engines to be Powered with Natural Gas, Transport na Alternativnom Toplive/Transport on Alternative Fuel, 4(34), pp. 29-32.

3. Luksho, V.A., 2015, A Complex Method of Increasing Energy Efficiency of Gas Engines with High Compression Ratio and Shortened Intake and Exhaust Strokes, Ph.D. thesis, NAMI, Moscow, 365 p.

4. Ivan S. Ivković, Snežana M. Kaplanović, Branko M. Milovanović, 2017, Influence of Road and Traffic Conditions on Fuel Consumption and Fuel Cost for Different Bus Technologies. Thermal Science, 21(1B), pp. 693-706.

5. José Geiger, Peter Heuser, Sven Lauer, Berthold Huchtebrock, Harsh Sankhla, 2013, Combustion System Development for a Large Bore Gas Engine - Efficient combination of Simulation and Experiment, Paper no 80, $27^{\text {th }}$ SIMAC Congress, Helsinki

6. Klausner, J., Lang J., Trapp, C., 2011, J624 - Der weltweit erste Gasmotor mit zweistufiger Aufladung, MTZ Motortechnische Zeitschrift Ausgabe, 04

7. Grotz, M., Böwing, R., Lang, J., Thalhauser, J., Christiner, P., Wimmer, A., 2015, Efficiency Increase of a High Performance Gas Engine for Distributed Power Generation, 6th CIMAC Cascades. Dual fuel and gas engines Their Impact on Application, Design and Components

8. Kudryavtzev, A., Lomashov, V., 2010, Belaz Trucks of XXI Century with DM Family Gas Diesel Engines, AvtoGasoZapravochniy komplex + Alternatvnoye toplivo/AutoGasFillingComplex + Alternative Fuel, 3, pp. 3-6.

9. Kapustin, A.A., 2008, Fuel Feed and Control System of a Gas Diesel Engine Operating on Natural Gas. Transport na alternativnom toplive/Transport on Alternative Fuel, 4, pp. 46-49.

10. Grehov, L.V., Ivsachenko, N.A., Markov, V.A., 2010, On Ways to Improve the Gas Diesel Cycle, AvtoGasoZapravochniy komplex + Alternatvnoye toplivo/AutoGasFillingComplex + Alternative Fuel, 7(100), pp. 10-14.

11. Imhof, D., Tsuru, D., Tajima, H., Takasaki, K, 2013, High-Pressure Natural Gas Injection (GI) Marine Engine Research with a Rapid Compression Expansion Machine, Paper no 12, 26th SIMAC Congress, Shanghai

12. Mikulski, M., Wierzbicki, S., 2017, Validation of a Zero-Dimensional and Two-Phase Combustion Model for Dual-Fuel Compression Ignition Engine Simulation, Thermal Science, 21(1B), pp. 387-399.

13. Shatrov, M. G., Golubkov, L. N., Dunin, A. Yu., Yakovenko, A. L., Dushkin, P. V., 2015, Influence of high injection pressure on fuel injection perfomances and diesel engine working process, Thermal science, 19(6), pp. 2245-2253.

14. Khatchijan, A.S., Sinyavskiy, V.V., Shishlov, I.G., Karpov, D.M., 2010, Modeling of Parameters and Characteristics of Natural Gas Powered Engines, Transport na Alternativnom Toplive/Transport on Alternative Fuel, 2010, 3(15), pp. 14-19. 